\title{
A Journey Through Time: From The Present Value To The Future Value And Back Or: Retirement Planning: A Comprehensible Application Of The Time Value Of Money Concept
}

Carolin E. Schmidt, Heilbronn University, Germany

\begin{abstract}
Real-life applications of financial concepts are a valuable method to get students engaged in financial topics. While especially non-finance majors often struggle to understand the importance of financial topics for their personal lives, applying these theories to real-life examples can significantly improve their learning experience and increase their understanding. This teaching case demonstrates how the time value of money concept can be applied to one's private retirement planning. Because of its simple assumptions, the case is targeted at an audience with little financial knowledge and can be used in finance as well as in accounting classes.
\end{abstract}

Keywords: Time Value of Money; Retirement Planning; Private Pension Scheme; Future Value; Present Value

\section{INTRODUCTION}

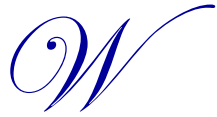
hile many financial theories are hard to grasp for non-finance majors or general interest readers, there is one important task in everyone's life to which one specific financial concept can easily be applied and which should not be neglected: retirement planning. Moreover, young people very often shy away from retirement planning because they don't know how to do it or underestimate the effect of early savings. The calculations in this case are kept simple, i.e. I assume constant interest rates and yearly annuities and the absence of taxes or inflation. The case requires some basic knowledge of compounding but could as well be handed out towards the end of an introduction to finance or accounting class.

\section{THE TIME VALUE OF MONEY}

\section{One-Period Compounding and Discounting}

A dollar today is not the same as a dollar next year: one dollar received today can be invested and grow to more than one dollar in one year's time:

$$
X_{0}(1+i)=X_{1}
$$

where $\quad \mathrm{X}_{0}=$ today's bank balance (present value, PV)

$$
\begin{aligned}
& \mathrm{X}_{1}=\text { account balance one year from now (future value, FV) } \\
& \mathrm{i}=\text { interest rate }
\end{aligned}
$$

Every dollar that is saved today at a rate of, say, $10 \%$ thus yields $\$ 1 \times 1.1=\$ 1.1$ in the future. But instead of solving for the FV we can also solve for the PV:

$$
X_{0}=P V=\frac{X_{1}}{1+i}
$$


While the calculation in equation (1) is called compounding, the calculation in the equation (2) is called discounting. This formula gives us the answer to the question: how much money has to be in our account today in order to accumulate to a specific amount in the future? If our bank balance in one year's time should be $\$ 1.10$ and the interest rate remains unchanged, then we have to save today. It is easy to show this using a bank account representation:

$$
X_{0}=P V=\frac{1.10}{1.1}=1.00
$$

\begin{tabular}{l|l}
\hline & Year 1 \\
\hline Beginning-of-year balance & $\$ 1.00$ \\
\hline+ Interest $(10 \%)$ & $\$ 0.10$ \\
\hline = End-of-year balance & $\$ 1.10$ \\
\hline
\end{tabular}

\section{Compounding and Discounting Over Longer Periods}

This concept can easily be extended to longer periods by solving the formula for interest on interest:

$$
X_{0}(1+i)^{2}=X_{2}
$$

for the PV:

$$
X_{0}=P V=\frac{X_{2}}{(1+i)^{2}}
$$

If we want to know today's required savings that allow us to withdraw $\$ 2$ from our account in two years' time (right after interest has been credited to the account at the end of the year), the result is

$$
X_{0}=P V=\frac{2.00}{(1.1)^{2}}=1.65
$$

In other words, we just discount $\mathrm{X}_{2}$ over our investment horizon of 2 periods. The bank balance will then look as follows:

\begin{tabular}{l|l|l}
\hline & Year 1 & Year 2 \\
\hline Beginning-of-year balance & $\$ 1.65$ & $\$ 1.815$ \\
\hline + Interest $(10 \%)$ & $\$ 0.165$ & $\$ 0.1815$ \\
\hline - Withdrawal & $\$ 0.00$ & $\$ 2.00$ \\
\hline End-of-year balance & $\$ 1.815$ & $\$ 0.00$ \\
\hline
\end{tabular}

\section{Compounding and Discounting Multiple Payments}

A pension, however, should not consist of one single future payment but of a stream of payments, a so-called annuity. For this, we can simply co mb ine the two above calculations (3) and (6) to create a series of two cash flows: by simply adding the two PV's, we can generate two future payments - one that we receive in one year's time and another one that we receive in two years' time. In short, if we deposit $\$ 1+\$ 1.65=\$ 2.65$ in a bank account today at an annual interest rate of $10 \%$, we can withdraw $\$ 1.10$ at the end of the first and $\$ 2$ at the end of the second year: 


\begin{tabular}{|c|c|c|}
\hline & Year 1 & Year 2 \\
\hline Beginning-of-year balance & $\$ 2.65$ & $\$ 1.815$ \\
\hline+ Interest $(10 \%)$ & $\$ 0.265$ & $\$ 0.1815$ \\
\hline - Withdrawal & $\$ 1.10$ & $\$ 2.00$ \\
\hline$=$ End-of-year balance & $\$ 1.815$ & $\$ 0.00$ \\
\hline
\end{tabular}

Formally, the PV is calculated as follows:

$$
X_{0}=P V=\frac{X_{1}}{1+i}+\frac{X_{2}}{(1+i)^{2}}=\frac{1.10}{1.1}+\frac{2.00}{(1.1)^{2}}=2.65
$$

In many finance textbooks, discounting is graphically depicted using a timeline:

Figure 1. Textbook illustration of discounting

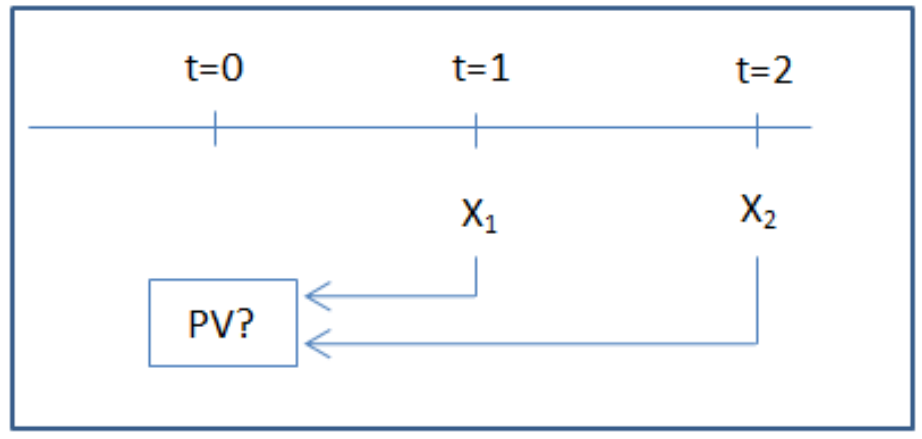

In general, arrows to the left symbolize that the amounts $\mathrm{X}_{1}$ and $\mathrm{X}_{2}$ should be discounted, which leads to the calculation of a $P V$ by adding up the discounted X's:

$$
P V=\frac{X_{1}}{1+i}+\frac{X_{2}}{(1+i)^{2}}
$$

By contrast, compounding is typically drawn using arrows to the right, and results in the $F V$ by adding up the compounded X's:

$$
F V=X_{0}(1+i)^{2}+X_{1}(1+i)
$$

Figure 2. Textbook illustration of compounding

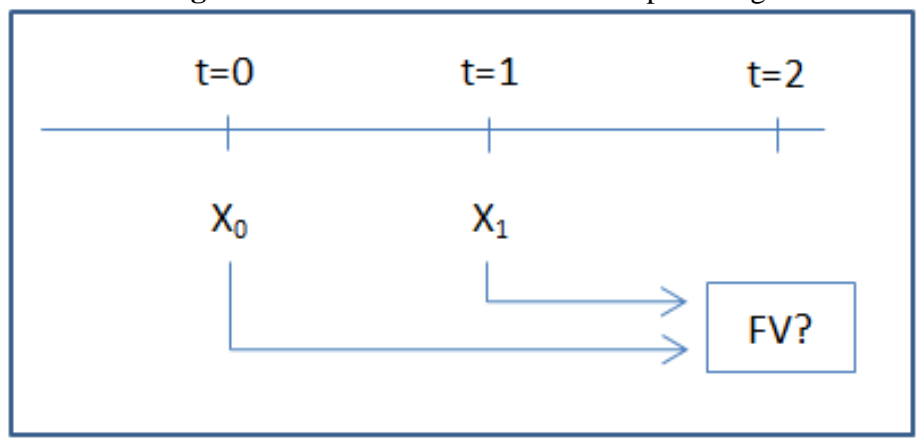




\section{RETIREMENT PLANNING}

While planning our retirement, we implicitly combine Figures (1) and (2). Let us assume that we start saving money this year and deposit an amount $\mathrm{X}$ in our account at the end of each year. We retire 40 years fro $\mathrm{m}$ today in $\mathrm{t}=40$ and, from then on, live on our savings and pay ourselves an ordinary annuity $Y=50,000$ until we pass away in $t=65$, as illustrated in Figure 3:

Figure 3. Textbook illustration of retirement planning

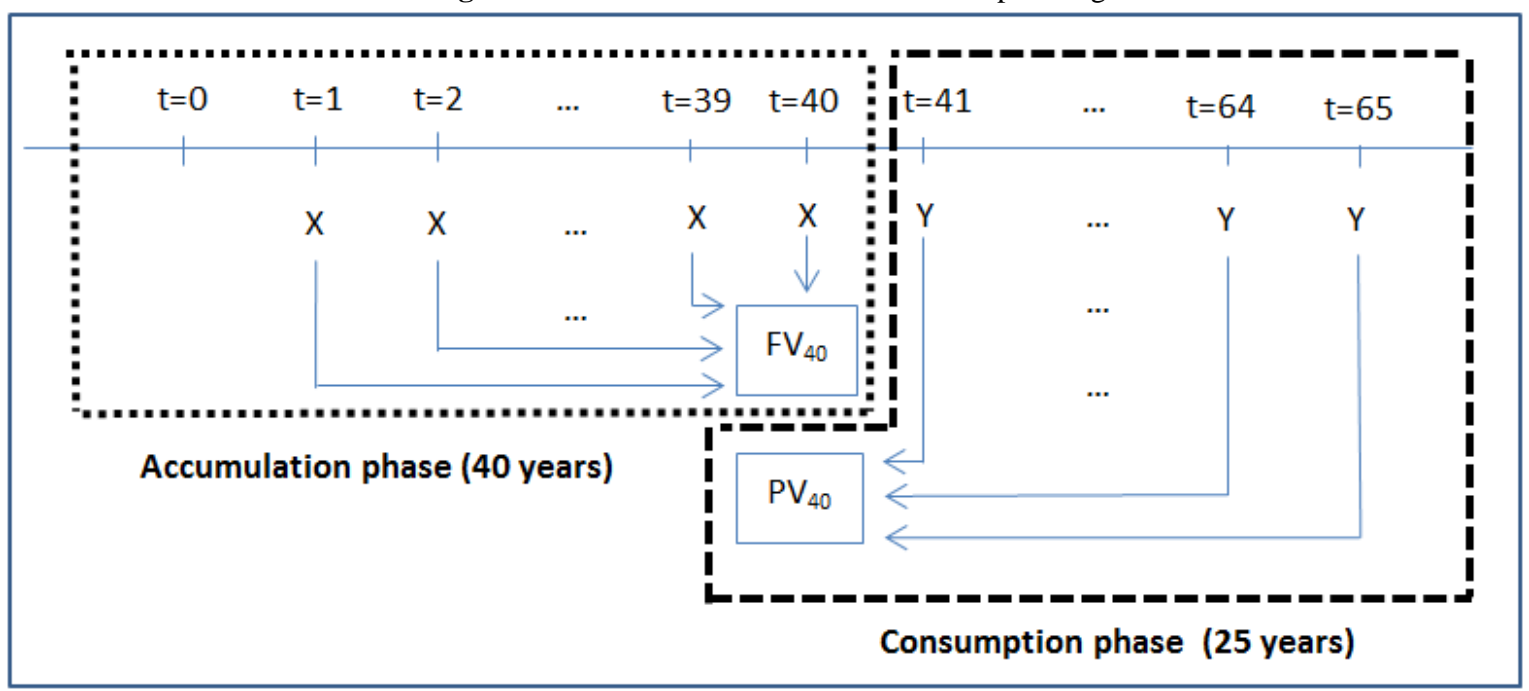

To solve this problem, the FV and the PV have to be identical since this is just the amount of money in our bank account that generates a constant 25 -year income stream of 50,000. Because $\mathrm{Y}$ is given, we will start with the dashed box.

Step (1): Determine the amount that we have to have saved at the beginning of our retirement (dashed line):

It is now easy to calculate a PV that can satisfy our consumption needs during our retirement. Using the above assumptions, let us suppose that we believe that an annuity of $\$ 50,000$ at the end of each of the 25 years will be enough. Then we have to discount each single payment over the appropriate number of periods:

Even though this is quickly done with spreadsheets, the calculation is too long for solving it manually. A short-cut formula for the PV of an ordinary annuity, i.e. of an annuity that is paid at the end of a period, is:

$$
\begin{aligned}
P V_{40} & =\frac{Y}{1+i}+\frac{Y}{(1+i)^{2}}+\frac{Y}{(1+i)^{3}}+\ldots+\frac{Y}{(1+i)^{25}} \\
& =\frac{50,000}{1.1}+\frac{50,000}{(1.1)^{2}}+\frac{50,000}{(1.1)^{3}}+\ldots+\frac{50,000}{(1.1)^{25}} \\
P V & =Y\left(\frac{q^{t} 1}{q^{t} \times i}\right)
\end{aligned}
$$

where $\mathrm{A}=$ ordinary annuity $\mathrm{q}=1+\mathrm{it}=$ number of periods.

Please note that this formula works only with end-of-period, constant payments and a constant interest rate. 
Thus, the bank balance in $\mathrm{t}=40$ should be equal to

$$
P V_{40}=50,000\left(\frac{(1.1)^{25} 1}{(1.1)^{25} \times 0.1}\right)=453,852
$$

in order to generate a constant cash flow stream of $\$ 50,000$ at the end of each year over the following 25 years (assuming a constant interest rate of $10 \%$ ). Figure 4 represents the dashed part of Figure 3.

Figure 4. Graphical illustration of the 25-year consumption phase

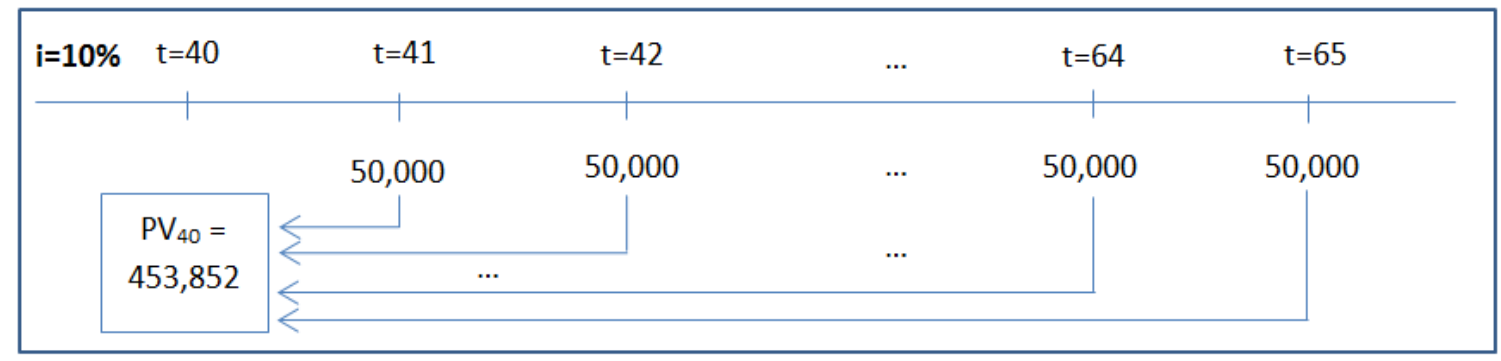

\section{Step (2): Determine the yearly amounts that we have to save during our working life (dotted line):}

Now that we know the required bank balance at the beginning of our retirement in $t=40$, we can change perspectives and ask ourselves how much we have to deposit every year in order to accumulate $\$ 452,852$. Compounding results in

$$
\begin{aligned}
F V_{40} & =X(1+i)^{39}+X(1+i)^{38}+\ldots+X \\
& =X(1.1)^{39}+X(1.1)^{38}+\ldots+X \\
& =P V_{40}=453,852 .
\end{aligned}
$$

Please note that the first payment yields interest for only 39 periods since it is deposited at the end of the first year until the end of the $40^{\text {th }}$ year. Analogously, the very last payment does not yield any interest since it is deposited in the very last logical second of our saving scheme.

Again, there is a shorter formula that applies for ordinary annuities and constant interest rates:

$$
F V=X\left(\frac{q^{t} 1}{i}\right)
$$

Plugging in our values for $\mathrm{q}$ and $\mathrm{t}$, equating equation (10) with $\mathrm{PV}_{40}=453,852$ and solving for $\mathrm{X}$ gives us the result:

$$
\begin{aligned}
& F V_{40}=X\left(\frac{(1.1)^{40} 1}{0.1}\right)=453,852 \\
& \Leftrightarrow \\
& X=\frac{453,852}{\left(\frac{(1.1)^{40} 1}{0.1}\right)}=1,025.44
\end{aligned}
$$

Please note again that despite the first payment yield ing interest only over 39 years, we have to plug in $t=40$ because this is our saving horizon. 
An ordinary annuity of $\$ 1,025.44$ over a period of 40 years deposited in an account with a return of $10 \%$ yields a FV of 453,852 which is just enough to satisfy our consumption needs during our 25 -year retire ment. Figure 5 shows the dotted part of Figure 3.

Figure 5. Graphical illustration of the 40-year accumulation phase

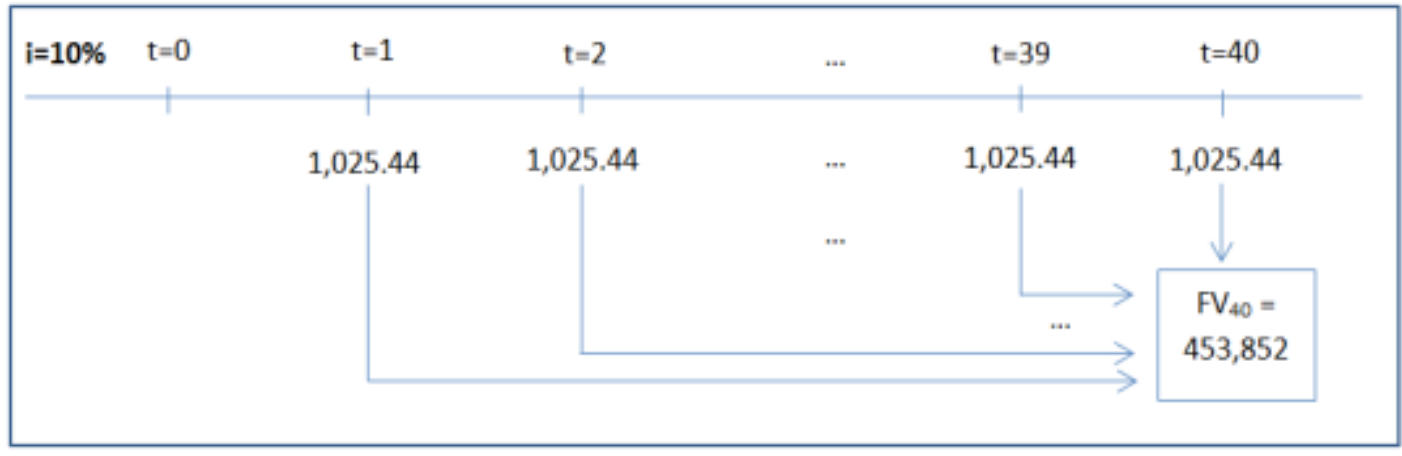

As an additional illustration, Figure 6 depicts the total bank balance at the end of each year during the entire period of 65 years. The calculations are designed such that after our final consumption in $\mathrm{t}=65$ the balance is zero.

Figure 6. End-of-y ear bank balance during the accumulation and consumption phase

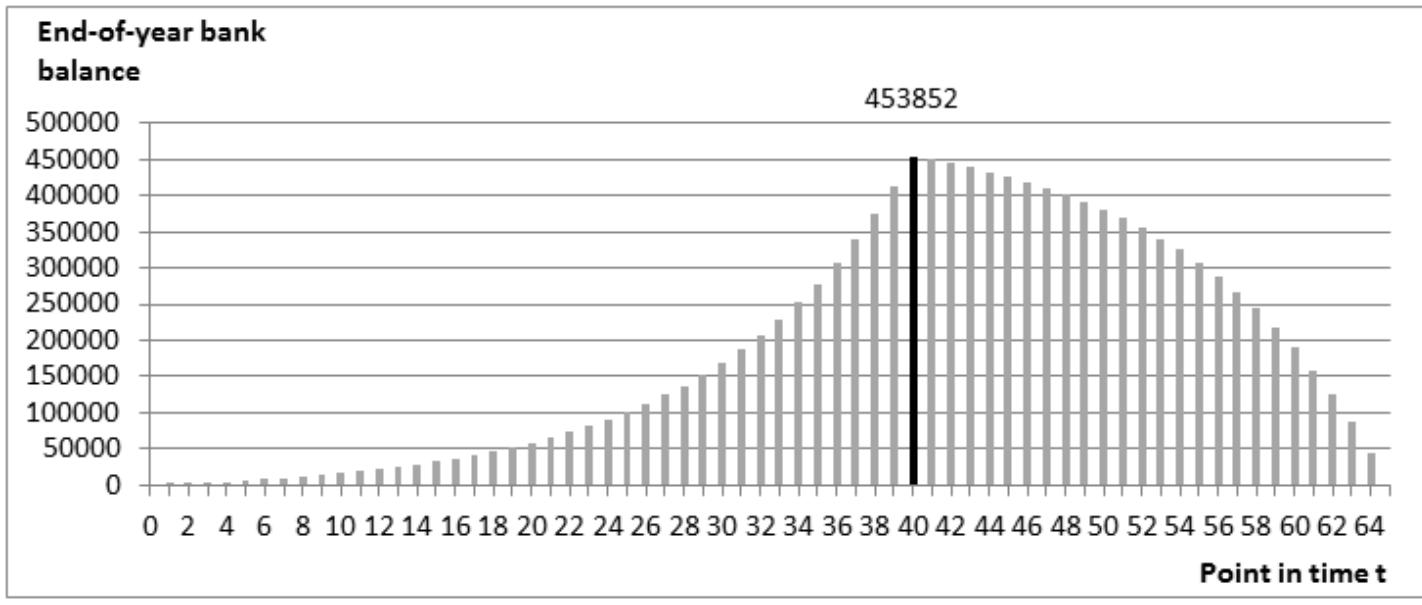

\section{QUESTIONS}

1. Assuming a working life of 30 years and an interest rate of $10 \%$, determine the required ordinary annuity to be able to consume $\$ 60,000$ at the end of each year over 35 years of retirement.

2. Now suppose you postpone your accumulation phase and make your first deposit not at the end of this year but at the end of the $5^{\text {th }}$ year, i.e. you save over 25 years only. The remain ing assumptions from problem 1 remain unchanged. How much do you have to lay aside per year? How much more or less in percentage terms is that compared to the amount in problem 1 ?

3. Suppose that you can deposit a constant amount of $\$ 20,000$ at a yearly rate of $5 \%$ at the end of every year over 20 years. How much can you consume yearly over a period of 40 years?

4. Suppose you'd like to invest your money in shares rather than in a bank account during your saving period of 40 years. You expect an annual return of $12 \%$. When you retire, however, you plan to sell your shares and deposit the entire proceedings in a low-risk bank account yielding a return of just $2 \%$. You'd then like 
to consume $\$ 50,000$ over 25 years at the end of each year. How much do you have to invest in shares at the end of each year?

\section{TEACHING NOTES AND SOLUTIONS}

Problem 2 is rather challenging and not suitable for every readership. Instructors of introductory classes might choose to skip this problem.

1.

$$
\begin{aligned}
& P V_{30}=60,000\left(\frac{\left.(1.1)^{35} \frac{1}{\left.(1.1)^{35} \times 0.1\right)}\right)=578,649.54}{F V_{30}=X\left(\frac{(1.1)^{30} 1}{0.1}\right)=578,649.54 \Leftrightarrow X=3,517.75}\right.
\end{aligned}
$$

2. $P V_{30}=578,649.54$

$$
F V_{30}=X\left(\frac{(1.1)^{25} 1}{0.1}\right)=578,649.54 \Leftrightarrow X=5,883.75
$$

This amount is $5,883.75 / 3,517.75=1.67$ times the size of the amount in problem 1 or roughly twothirds higher. This problem should point out the importance of early savings.

3.

$$
\begin{aligned}
& F V_{20}=20,000\left(\frac{1.05^{20} 1}{0.05}\right)=661,319.08 \\
& P V_{20}=Y\left(\frac{(1.05)^{40} 1}{(1.05)^{40} \times 0.05}\right)=661,319.08 \Leftrightarrow Y=38,540.46
\end{aligned}
$$

4.

$$
\begin{aligned}
& P V_{40}=50,000\left(\frac{(1.02)^{25} 1}{1.02^{25} \times 0.02}\right)=976,172.82 \\
& F V_{40}=X\left(\frac{(1.12)^{40} 1}{0.12}\right)=976,172.82 \Leftrightarrow X=1,272.56
\end{aligned}
$$

In my experience the graphical illustration of present and future values helps students better understand the concept. Also the bank account representation serves as a proof that the saving and consumption strategy leads to a bank balance in $\mathrm{t}=\mathrm{T}$ equal to zero.

\section{POSSIBLE EXTENSIONS}

Of course this is a very basic illustration of a pension scheme. The assumptions were intentionally kept simple in order not to discourage non-finance students. In an advanced finance course or towards the end of the semester, instructors can make the computations more complex with:

- Monthly payments and interest rates

- Beginning-of-period payments

- $\quad$ Varying interest rates (e.g., upward-sloping yield curve)

- Taxes

- Inflation or other growth rates

\section{AUTHOR BIOGRAPHY}

Carolin E. Schmidt holds a Bachelor in International Business Administration and a Master in Accounting and Finance. She is a researcher and lecturer at Heilbronn University in Heilbronn, Germany where she teaches undergraduate classes in financial management, international finance, European financial markets and corporate finance. Her research interests are in the areas of finance and economics as well as internationalization and teaching methods for higher education. 